\title{
Performance Evaluation of Cementitious Composites Containing Granulated Rubber Wastes, Silica Fume, and Blast Furnace Slag
}

\author{
Maléki Tagba ${ }^{1}\left(\mathbb{D}\right.$, Shujin Li ${ }^{1, *}$, Mingjie Jiang ${ }^{1, *}, \mathrm{Xu} \mathrm{Gao}^{1}$, Mohamed Larbi Benmalek ${ }^{2}$, Salima Boukour ${ }^{2,3}$ \\ and Chuanqi Liu ${ }^{1}$ \\ 1 School of Civil Engineering and Architecture, Wuhan University of Technology, Wuhan 430070, China; \\ tagba.bertrand@yahoo.fr (M.T.); x.gao@whut.edu.cn (X.G.); liuchuanqi@whut.edu.cn (C.L.) \\ 2 Civil Engineering and Hydraulic Laboratory, University of 8 May 1945, Guelma 24000, Algeria; \\ bmalek2@yahoo.fr (M.L.B.); salimabouk@hotmail.fr (S.B.) \\ 3 Department of Science and Technology, University Center Abdelhafid Boussouf, Mila 43000, Algeria \\ * Correspondence: sjli@whut.edu.cn (S.L.); jiangmingjie@whut.edu.cn (M.J.)
}

Citation: Tagba, M.; Li, S.; Jiang, M.; Gao, X.; Benmalek, M.L.; Boukour, S.; Liu, C. Performance Evaluation of Cementitious Composites Containing Granulated Rubber Wastes, Silica Fume, and Blast Furnace Slag. Crystals 2021, 11, 632. https:// doi.org/10.3390/cryst11060632

Academic Editor: Tomasz Sadowski

Received: 4 May 2021

Accepted: 27 May 2021

Published: 1 June 2021

Publisher's Note: MDPI stays neutral with regard to jurisdictional claims in published maps and institutional affiliations.

Copyright: (c) 2021 by the authors. Licensee MDPI, Basel, Switzerland. This article is an open access article distributed under the terms and conditions of the Creative Commons Attribution (CC BY) license (https:/ / creativecommons.org/licenses/by/ $4.0 /)$.

\begin{abstract}
In this study, rubberized cementitious materials are produced with recycled rubber waste as an alternative to fine aggregate. Mixtures with different additions to rubber wastes (RW), silica fume (SF), and blast furnace slag (BFS) have been designed and characterized. Hardened properties including compressive and bond strength, shrinkage, water-accessible porosity, rapid chloride migration, and microstructure were investigated. The results show that the addition of SF and BFS improves the performances of rubberized mortars and reduces shrinkage. The incorporation of $5 \%$ RW with 20\% BFS increases compressive strength and reduces water-accessible porosity. Ion chloride resistance was enhanced by a combination of $15 \% \mathrm{RW}, 8 \% \mathrm{SF}$, and $20 \% \mathrm{BFS}$. The addition of SF and BFS as cement replacement improves the performance of mortars due to their filling effect and a pozzolanic reaction, which has been verified by a microstructural analysis.
\end{abstract}

Keywords: rubber waste; rubberized mortar; mechanical characteristics; pull-out test; bond strength; chloride mitigation

\section{Introduction}

Energy conservation and reduction of carbon emissions have become critical in the world [1], and it is well known that 8 to $10 \%$ of global $\mathrm{CO}_{2}$ emissions are produced by the cement industry, which is seen as one of the leading causes of climate change [2]. Concrete typically contains approximately $12 \%$ cemented materials, $8 \%$ water, and $80 \%$ aggregates. The extraction, processing, and transport of vast quantities of aggregates, together with raw materials required each year for cement production, consumes a considerable amount of energy and harms the ecology of the planet [3]. Faced with the growing demand for material resources and the need to preserve the environment, it is necessary to explore and study possibilities for the re-use and recovery of waste and industrial by-products, especially in the field of civil engineering [4].

Used tires are non-hazardous waste, but their storage presents a risk to the environment and humanity if there is no additional fire prevention at the storage site; this creates a significant waste management problem. The rubber industry is one of many sources of waste and produces above 1.5 billion new tires worldwide each year [5]. For example, in Europe, some 3.4 million tons of old tires are disposed of each year [6]. In India, 112 million discarded tires are produced annually [7] and in 2018, around 14.58 million tons of used tires have been produced in China [8]. Low bulk density, drainage capacity, compressibility and thermal conductivity of tire waste can be used in geotechnical and civil engineering applications such as light backfills, prevention of frost-heating, landfill drainage, road and highway pavement asphalt, sports surfacing, and filling materials for turf grass [9-12]. 
Several studies, including the incorporation of rubber aggregates into cement matrices, have found rubber aggregates to be viable in substitution of sand and gravel in concretes and mortars. Thomas et al. [13] studied the performances of high-strength rubber concrete containing rubber from used tires (size from $0 \%$ to $20 \%$ in multiples of $2.5 \%$ ); it was found that water absorption and abrasion resistance were better than that of the reference concrete, while depth of water penetration, pull-off, flexural tensile, and compressive strength of rubber concrete were less than that of the reference mix. Ganjian et al [14] also investigated the performances of concrete mixes incorporating 5\%,7.5\%, and $10 \%$ of discarded tire rubber as aggregate and cement replacements and the results showed a 28-day compressive strength reduction-about 10 to $23 \%$ and 20 to $40 \%$ - and a flexural strength of about $37 \%$ and $29 \%$ for aggregates and for the cement replacement, respectively. Valente and Sibai [15] conducted a review in which various amounts of waste tire powder were combined with cement concrete mixtures to produce a final product with mechanical properties suitable for engineering applications. It was concluded that a good compressive strength can be obtained by replacing 30\% of the powdered tire with crushed sand. Compressive strength decreases as the percentage of aggregation between crumb rubber and crushed sand increases. Aggregation replacement of crumb rubber and crushed sand results in a density reduction of around $10 \%$. The modulus of elasticity is proportional to the percentage of rubber added: the more rubber added to concrete, the less elastic the product. Furthermore, less tough concrete means greater strength. The addition of rubber to concrete, on the other hand, increases its toughness. Sambucci et al. [16] conducted a preliminary physical-mechanical analysis on environmentally friendly mortars made of recycled rubber aggregates derived from end-of-life tires that are compatible with the extrusion-based printing process. To partially/completely replace the sand, 50\% and $100 \%$ rubber powder (size $0-1 \mathrm{~mm}$ ), 50\% and 75\% rubber granules (size $2-4 \mathrm{~mm}$ ) were used. The results show that the rubber aggregates increase the fluidity and ductility of the mixture, promoting better inter-layer adhesion than the neat mix, resulting in greater mechanical isotropy but decreasing mechanical strength. The incorporation of rubber granules from used tires into cementitious materials is detrimental to compressive strength and tensile strength [17-20]. In return, the composite obtained has a greater ductility and strain capacity [21-27]. Grdić et al. [26] reported an increase in the concrete ductility in the range of $25 \%, 81.25 \%$, and $93.75 \%$, by partially replacing natural sand with crumb rubber (size 4-0.5 $\mathrm{mm}$ ) at levels of $10 \%, 20 \%$, and $30 \%$, respectively, by volume. Huang et al. [27] reported that the increase in the tensile strain capacity was $11.11 \%, 16.67 \%, 44.44 \%$, and $66.67 \%$ with the inclusion of $10 \%, 20 \%, 30 \%$, and $40 \%$ rubber sand, respectively.

Previous studies have mentioned that immersing the waste rubber into a solution of $\mathrm{NaOH}$ [28], covering it with a thin layer of cement [29], using styrene-butadiene rubber (SBR) [30], using organic sulfur [31], and using a silane coupling agent with a coating [32] all contributed to improved strength. Improved properties were also shown in rubber concrete with addition of silica fume (SF) [33,34], fly ash [35,36], calcareous [37], steel fibers [38], and polyvinyl alcohol fibers (PVA) [39-42]. Copetti et al. [34] replaced Portland cement $(7.5 \%$ and $15 \%$ ratios) with silica fume in rubber concrete, up to $80 \%$ gains in compressive strength 28 days with $30 \%$ rubber replacement were resulted. The properties of self-compacting rubberized concrete incorporating polypropylene (PP) and steel fibers were studied by Aslani et al. [38]. As a replacement for $20 \%$ of fine aggregates and $0.1 \%$, $0.15 \%, 0.2 \%, 0.25 \%, 0.25 \%$ of PP fibers and $0.25 \%, 0.5 \%, 0.75 \%, 1 \%$ for steel fibers, crumb rubber with size of 2 to $5 \mathrm{~mm}$ was used. With the increase in the content of steel fibers, the results show a minor increase in compressive and tensile strengths. The behavior of concrete incorporating crumb rubber as a partial replacement of fine aggregate and polyvinyl alcohol fibers as cement addition was studied by Sadiq et al. [39]. $1 \%$ and $2 \%$ of PVA (by mass of cement), 5\% and 10\% of crumb rubber into concrete (by weight of fine aggregate) were incorporated and a positive impact on the engineering properties of concrete was shown by PVA. 
Although RW-incorporated cementitious materials were designed and some performances, especially mechanical properties, were identified, it is still necessary to systematically build relations between key design parameters and micro-macro properties. This study aimed to investigate the effect of mineral additives such as silica fume and blast furnace slag, on the physical-mechanical, durability, and microstructural properties of rubberized mortar. Where fine aggregate was replaced with rubber aggregate waste, cement was replaced by BFS and SF. Compressive and bond strength, shrinkage, water-accessible porosity, Rapid migration of chloride, SEM and XRD analysis were assessed and discussed.

\section{Materials and Test Procedures}

\subsection{Materials}

The cement used for all mortar mixtures is the OPC class 42.5 produced by Huaxin Cement in China. Its specific surface area and absolute density were $365 \mathrm{~cm}^{2} / \mathrm{g}$ and $2.56 \mathrm{~g} / \mathrm{cm}^{3}$, respectively. Fine aggregates with particle (size $\leq 5 \mathrm{~mm}$ ), absolute and apparent densities of 2.56 and $1.49 \mathrm{~g} / \mathrm{cm}^{3}$, respectively, were used as well as commercial $\mathrm{SF}$ and BFS. In the volume substitution of sand, the RW aggregates resulting from the mechanical grinding of old tires are used. These aggregates have a maximum size of $5.0 \mathrm{~mm}$; their absolute and apparent densities are 1.21 and $0.44 \mathrm{~g} / \mathrm{cm}^{3}$, respectively. Table 1 lists the chemical composition of OPC, SF, and BFS. For each mixture, the superplasticizer (polycarboxylic acid water reducing agent) was used in different percentages by weight of the binder to ensure the same workability with varying rubber particle proportions. At $0.1 \%$ by weight of the total binder, the stabilizer, Hydroxy Propyl Methyl Cellulose (HPMC), was used to avoid segregation of rubber particles because of the significant difference between their specific density and density of the sand. In order to improve the studied mortar matrix bonding, a synthetic aqueous dispersion resin (SIKALATEX) was used at a fixed cement weight of $7 \% .1 \mathrm{~kg} / \mathrm{L}$ is its density. For the treatment of the surface of rubber waste, sodium hydroxide $(\mathrm{NaOH})$ was used to improve adhesion between rubber waste and cement. The treatment was carried out by immersing the RW in an alkaline solution made by dissolving $10 \mathrm{~g}$ of $\mathrm{NaOH}$ pastilles in $90 \mathrm{~cm}^{3}$ of distillate water, resulting in a $10 \%$ concentration. The RW was immersed in this saturated aqueous solution for 20-30 minutes while agitating the mixture on a regular basis. The removal of excess $\mathrm{NaOH}$ adsorption on the surface of the RW required rinsing with distilled water. To ensure that all of the $\mathrm{NaOH}$ from the RW was removed, the $\mathrm{pH}$ of the solution was tested with a $\mathrm{pH}$ paper until it was equal to 7. Finally, the RW was dried in open air before use. The raw materials used and described earlier in this work are presented in Figure 1.

Table 1. Chemical composition of the OPC, SF, and BFS used (\%).

\begin{tabular}{cccccccc}
\hline & OPC & SF & BFS & & OPC & SF & BFS \\
\hline Oxydes & & $(\%)$ & & Oxydes & & $(\%)$ & \\
$\mathrm{CO}_{2}$ & - & 3.263 & -1.621 & $\mathrm{MnO}$ & - & 0.091 & 0.091 \\
$\mathrm{Na}_{2} \mathrm{O}$ & - & 1.000 & 0.326 & $\mathrm{ZnO}$ & - & 0.009 & - \\
$\mathrm{MgO}$ & 3.56 & 5.954 & 7.976 & $\mathrm{SeO}_{2}$ & - & 0.005 & - \\
$\mathrm{Al}_{2} \mathrm{O}_{3}$ & 4.89 & 10.134 & 15.495 & $\mathrm{Br}$ & - & 0.002 & - \\
$\mathrm{SiO}_{2}$ & 20.93 & 23.941 & 32.823 & $\mathrm{Rb} 2 \mathrm{O}$ & - & 0.004 & 0.003 \\
$\mathrm{P}_{2} \mathrm{O}_{5}$ & - & 0.034 & 0.018 & $\mathrm{SrO}$ & - & 0.110 & 0.125 \\
$\mathrm{SO}_{3}$ & 2.27 & 13.473 & 2.494 & $\mathrm{Y}_{2} \mathrm{O}_{3}$ & & 0.008 & 0.010 \\
$\mathrm{Cl}$ & - & 0.040 & - & $\mathrm{ZrO}_{2}$ & - & 0.040 & 0.051 \\
$\mathrm{~K}_{2} \mathrm{O}$ & 0.56 & 0.727 & 0.478 & $\mathrm{BaO}$ & - & 0.087 & 0.337 \\
$\mathrm{CaO}$ & 60.42 & 38.677 & 38.853 & $\mathrm{CeO}_{2}$ & - & 0.054 & - \\
$\mathrm{TiO}_{2}$ & - & 0.554 & 0.649 & & & & \\
$\mathrm{Fe}_{2} \mathrm{O}_{3}$ & 2.89 & 1.796 & 0.273 & & & & \\
Loss on ignition & 3.60 & - & - & & & & \\
\hline
\end{tabular}




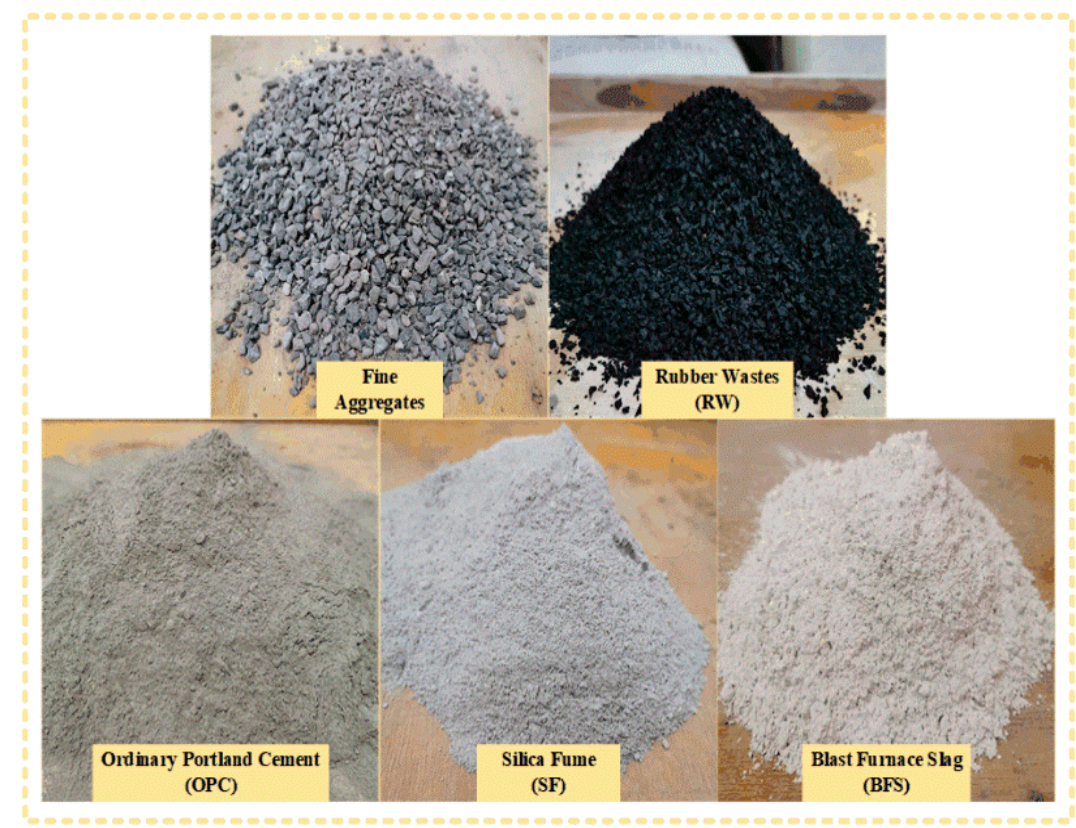

Figure 1. Raw materials used.

\subsection{Mixture Proportions and Sample Preparation}

In the laboratory, nine mortar mixtures containing the above-mentioned materials were produced, as shown in Table 2, where all the mixtures had a fixed water/binder ratio of 0.45 . Different percentages, by weight of the total binder, were used for the superplasticizer introduced in the blends. SF, BFS, and RW contents were used. By mass substitution of the cement, the SF content tested was $8 \%$ and the BFS content was $20 \%$. In addition, the RW contents tested were $5 \%, 10 \%$, and $15 \%$ by volume substitution of sand.

Table 2. The proportions of the mortar mixture used $\left(\mathrm{kg} / \mathrm{m}^{3}\right)$.

\begin{tabular}{cccccccccc}
\hline $\begin{array}{c}\text { Mortar } \\
\text { Mixture }\end{array}$ & OPC & $\begin{array}{c}\text { Fine } \\
\text { Aggregates }\end{array}$ & Water & RW & BFS & SF & Stabilizer & $\begin{array}{c}\text { SP-Plast } \\
\text { Resinous } \\
\text { Latex }\end{array}$ \\
\hline Ref & 450 & 1350 & 202.5 & 0 & 0 & 0 & 0 & 9.95 & 0 \\
5RW & 450 & 1282.5 & 202.5 & 31.91 & 0 & 0 & 0.45 & 5.22 & 31.5 \\
10RW & 450 & 1215 & 202.5 & 63.81 & 0 & 0 & 0.45 & 4.82 & 31.5 \\
15RW & 450 & 1147.5 & 202.5 & 95.72 & 0 & 0 & 0.45 & 5.49 & 31.5 \\
5RW+8SF & 414 & 1282.5 & 202.5 & 31.91 & 0 & 36 & 0.45 & 7.38 & 31.5 \\
5RW+20BFS & 360 & 1282.5 & 202.5 & 31.91 & 90 & 0 & 0.45 & 3.96 & 31.5 \\
10RW+8SF & 414 & 1215 & 202.5 & 63.81 & & 36 & 0.45 & 6.12 & 31.5 \\
10RW+20BFS & 360 & 1215 & 202.5 & 63.81 & 90 & 0 & 0.45 & 3.92 & 31.5 \\
15RW+8SF+20BFS & 324 & 1147.5 & 202.5 & 95.72 & 90 & 36 & 0.45 & 6.53 & 31.5 \\
\hline
\end{tabular}

Mortar samples were prepared using laboratory mixers. At slow speed, sand, cement, RW, BFS, and SF were blended for $3 \mathrm{~min}$. $80 \%$ water, the superplasticizer, the stabilizer and the resinous latex were added once the mixture was homogeneous and mixed at slow speed for 2 minutes. After that, the remaining 20\% of water was added and the mixtures were mixed for more than 3 minutes at rapid speed. Tests on the shaking table were carried out immediately to obtain plastic mixtures (workability comprise between 14-18 cm). After that, for each step, fresh mortar was poured into different plastic molds in 2 stages and vibrated for $30 \mathrm{~s}$, then sealed with plastic to keep the temperature inside wet for $24 \mathrm{~h}$. They were cured in water after demolding for 28 days in room temperature conditions. Figure 2 shows some photos of the specimens made in this work. 

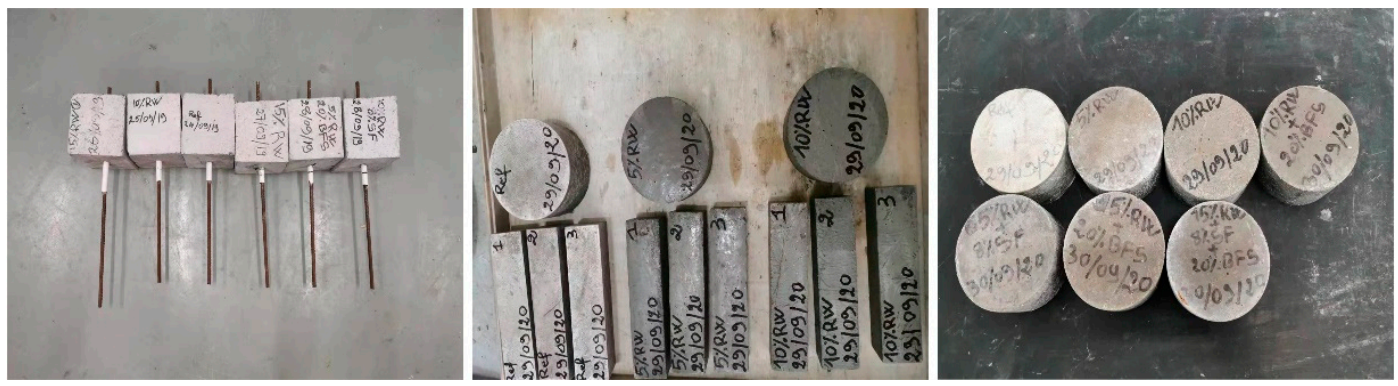

Figure 2. Specimens made.

\subsection{Test Procedures}

\subsubsection{Compressive Strength}

Compressive strength tests were carried out at 7 and 28 days in accordance with EN 196-1 and the measurements were carried out using an automated brake and compression resistance tester with a maximum power of $300 \mathrm{kN}$. The compressive strength was obtained from an average of three tests.

\subsubsection{Bond Strength}

Each specimen consisted of a mortar cube, $150 \mathrm{~mm}$ on each edge, with a single $10 \mathrm{~mm}$ diameter steel rod embedded vertically along the central axis for the bond strength test. The steel rods used were hot rolled deformed bars with deformations on their surface in the form of ribs. One-year bond strength was subsequently evaluated by performing a direct pull-out test on a $1000 \mathrm{kN}$ capacity microcomputer control electro-hydraulic suit universal testing machine (WA VW-1000kN) in accordance with the provisions of ASTM C2344 (ASTM 1988). The average bond strength was calculated according to the following formula:

$$
\tau \mathrm{av}=\frac{F}{(\pi \times \mathrm{d} \times 1)}
$$

where 1 is the embedment length $(\mathrm{mm}), F$ is the force $(\mathrm{N}), \mathrm{d}$ is the diameter of the reinforcing bar $(\mathrm{mm})$, and tav is the average bond strength $(\mathrm{MPa})$. The bond strength measurements were performed using three specimens of each mixture.

\subsubsection{Drying Shrinkage}

Drying shrinkage was measured according to KS F 2424. On three $4 \mathrm{~cm} \times 4 \mathrm{~cm} \times 16 \mathrm{~cm}$ mortar specimens with gage stud bolt embedded at both ends of the specimens, measurements of length changes were taken for each mixture. The mortar specimens were cured for 1 day, after demolding, at $20 \pm 3{ }^{\circ} \mathrm{C}$ in air. Then, changes in length were measured several times $(t)$ and the shrinkage was calculated using Equation (2) at any time up to 60 days:

$$
\varepsilon=\frac{\Delta l(t)}{L}
$$

where, $\Delta l(t)=$ difference between reading length at time $t$ (days), $L=$ initial reading length at $24 \mathrm{~h}$ after demolding $(\mathrm{mm})$ and $\varepsilon=$ drying shrinkage $(\mathrm{mm} / \mathrm{m})$.

\subsubsection{Porosity Accessible to Water}

Water-accessible porosity was measured by hydrostatic weighing in accordance with NF EN 18-459. Measurements were made after storage in water for three specimens of $4 \mathrm{~cm} \times 4 \mathrm{~cm} \times 16 \mathrm{~cm}$, for each mixture, at room temperature for up to 28 days. The difference in mass between a sample in the dry state and the same sample in the saturated state was calculated. 
For the calculation of the porosity accessible to water $P$, the following formula was used:

$$
P=\frac{M_{a i r}-M_{d r y}}{M_{a i r}-M_{\text {water }}}
$$

where, $M_{\text {air }}=$ Mass of the soaked sample $(\mathrm{g}), M_{d r y}=$ mass of the dry sample $(\mathrm{g})$, $M_{\text {water }}=$ Mass of the sample immersed in water $(\mathrm{g})$, and $P=$ porosity accessible to water $(\%)$.

\subsubsection{Rapid Chloride Migration}

The 28-day chloride resistance of mortars was assessed by Rapid Chloride Migration (RCM) in compliance with NT Build 492. The specimens for the test were $100 \mathrm{~mm} \times 50 \mathrm{~mm}$ disks. First, the disks were saturated with lime-saturated water and then the specimens were subjected for a certain period of time to an electrical potential. After that, by spraying $0.1 \mathrm{M}$ silver nitrate solution, the discs were fractured and the chloride ingress depths were obtained. The chloride diffusion coefficient can be calculated accordingly on the basis of the applied electrical potential, test time, and temperature before and after the test. Each reported value was the average of measurements of three tests for all mixtures.

\subsubsection{XRD Analysis}

The mineralological analysis of the materials used, which were reduced to powder, was carried out using the X-ray diffraction method. This method enables the various crystalline phases that make up the material to be defined. Each mineral has a characteristic $X$-ray diffraction spectrum, depending on the incidence $2 \theta$ of the X-ray source on their crystalline planes.

\subsubsection{SEM Analysis}

Microstructural analyzes were carried out at 14 months, mainly to verify the ITZ of the mortar samples. All the selected pieces were coated with epoxy resin and polished prior to the test. A back-scattered electron (BSE) detector was used to record micrographs. The working distance was set in the range of $10.2-14.8 \mathrm{~mm}$ for the SEM test, while the acceleration voltage was $20 \mathrm{kV}$.

\section{Results and Discussion}

\subsection{Compressive Strength}

The compressive strength of the tested specimens is shown in Figure 3. Indicated values are the average of three tests. With increasing rubber content, a progressive decline in compressive strength can be observed. There are two key reasons for the decrease in rubberized mortar strength. Firstly, the low elasticity modulus and the low resistance of the rubber particles mainly decrease mortar strength [43]. Secondly, the particles of rubber are highly hydrophobic, thereby increasing the porosity of the concrete matrix and thus reducing the strength $[25,44]$. The addition of SF and BFS may increase the rubberized mortar's compressive strength. Replacing $8 \%$ of cement by SF increased the compressive strength of the 5RW mix by $8.30 \%$ and $18.43 \%$ for 7 and 28 days, respectively, while replacing $20 \%$ of cement by BFS increased the compressive strength of the same mix by $15.58 \%$ and $21.32 \%$ for 7 and 28 days. Similarly, substituting $8 \%$ of cement by SF increased the compressive strength of the 10RW mix by $28.36 \%$ and $12.14 \%$ for 7 and 28 days, respectively, while substituting $20 \%$ of cement with BFS increased the compressive strength of the same mix by $30 \%$ and $28.93 \%$ for 7 and 28 days, respectively.

The increase in compressive strength following the addition of SF is due to its filling and pozzolanic effects $[33,45]$. This observation is attributed to the matrix densification and improvement of the interface of the rubber-cement paste due to the filling effect and silica fume pozzolanic reaction products. The surface treatment of rubber particles with $\mathrm{NaOH}$ and silica fume used as cement volume replacement contribute to the improvement of the interface of the rubber-cement matrix [46]. The role of silica fume in improving strength results is primarily due to the interaction of the free lime released by OPC clinker with 
reactive silica fume. This leads to the formation in the samples of additional quantities of calcium silicate hydrates, resulting in an increase in the strength values of the RW+SF cured mortars. Compared to the $15 \%$ RW mix, the combination of $8 \%$ SF and $20 \%$ BFS with $15 \%$ RW increases the compressive strength by $26.30 \%$ and $24.63 \%$ for 7 and 28 days, respectively, but compared to the reference mortar, there was a decrease of $63.63 \%$ and $59.98 \%$ for 7 and 28 days, respectively.

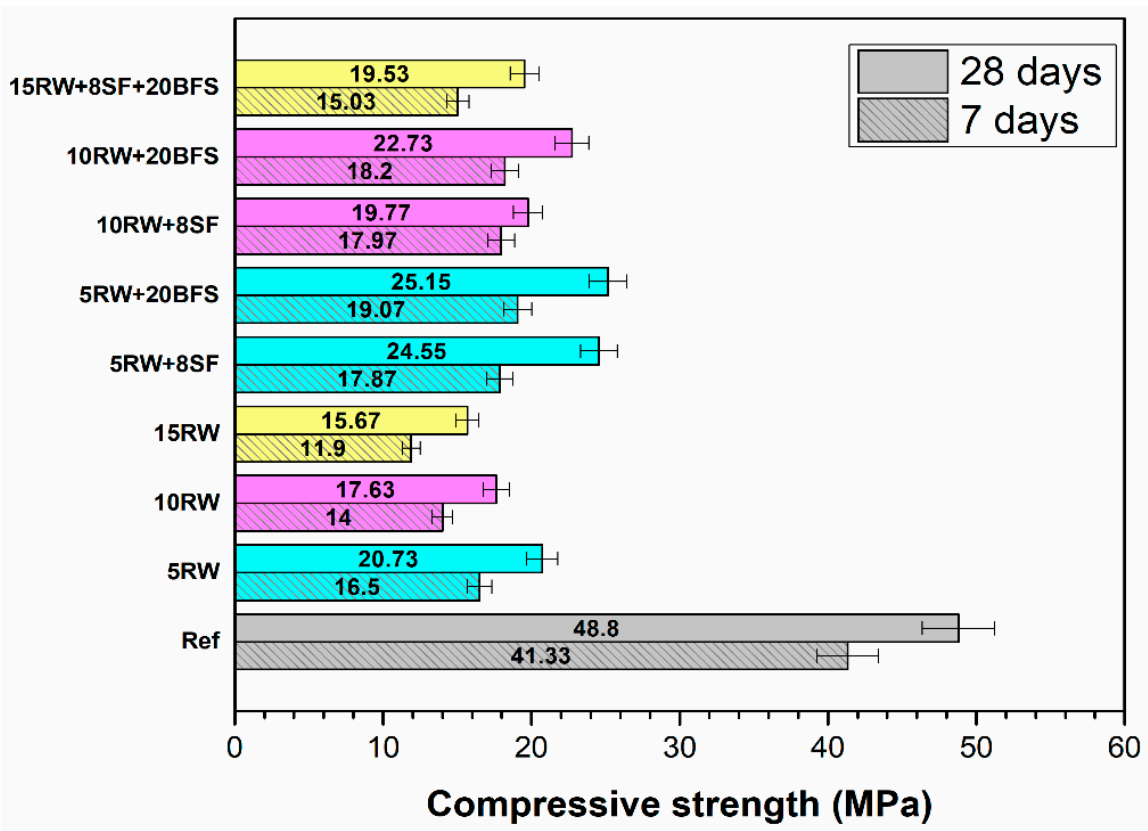

Figure 3. Compressive strength of the tested specimens.

\subsection{Bond Strength}

Figure 4 shows the pull-out test results of all mixtures after one year of curing. The bond strength for the rubber waste mortar is $18.58 \mathrm{MPa}, 16.35 \mathrm{MPa}$, and $13.88 \mathrm{MPa}$, for the 5RW, 10RW, and 15RW mixture, respectively, while the bond strength of the reference mortar was $28.84 \mathrm{MPa}$, a decrease of $35.57 \%, 43.30 \%$, and $51.87 \%$. The effect of rubber was to decrease the strength of the bond, because when the rubber particles were added into the mixture [47], the effective bond surface area of the specimens was reduced. The weak adherence between the cement paste and rubber particles may be due to this negative effect of rubber on the bond strength. According to [48], the flexibility of the rubber aggregates, the weak interfacial bond between the rubber aggregates and the cement paste, and the interface cracking result in decreased friction between the reinforcement steel bar and its surroundings. According to [49], the reduction of the compressive strength due to the replacement of mineral aggregates with rubber particles has a direct influence on the bonding properties, since the compressive forces in the concrete cover resulting from the wedge action are limited to a fraction of the compressive strength and the rebar-rubberized concrete interface, on the other hand, is often potentially subject to other types of friction than standard concrete, with rubber particles clamping the rebar ribs and providing various mechanisms of energy dissipation.

The 5RW+8SF and 5RW+20BFS combinations show a decrease in bond strength of $65.56 \%$ and $50.62 \%$, respectively, compared to the Ref. mixture and a decrease of $46.55 \%$ and $23.35 \%$, respectively, compared to the 5RW mixture. The $10 \mathrm{RW}+8 \mathrm{SF}$ and $10 \mathrm{RW}+20 \mathrm{BFS}$ shows a decrease of $56.20 \%$ and $43.55 \%$, respectively, compared to the Ref. mix and a decrease of $22.75 \%$ and $0.4 \%$, respectively, compared to the $10 \mathrm{RW}$ mix. For the $15 R W+8 S F+20 B F S$ combination, there was a decrease of $56.93 \%$ and $10.51 \%$, respectively, compared to the Ref. and 15RW mixtures. It is clearly noted that the addition of additives did not present a positive effect on the steel-cement matrix bonding as regards compres- 
sive strength. According to [50], there is a correlation between pull-off test results and compressive strength.

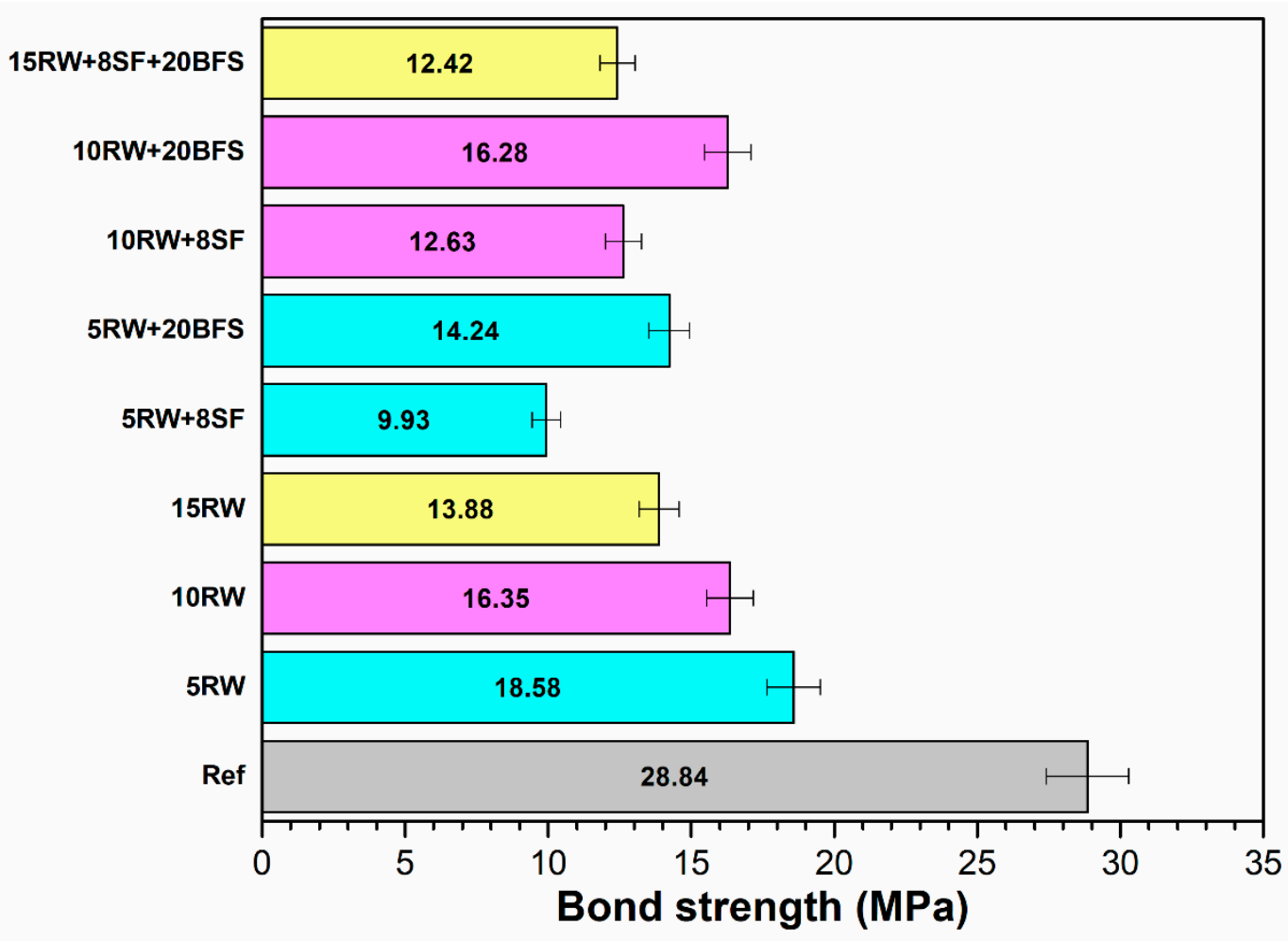

Figure 4. Bond strength of the tested specimens.

\subsection{Drying Shrinkage}

Figure 5a shows the change in drying shrinkage measured on all mortars as a function of time. This characteristic increases over time due to the progressive loss of capillary water from the mixes. The rubber aggregates incorporated in the study mixes increase the drying shrinkage at all ages with the increase in their contents compared to the mix without rubber aggregates. The increase in drying shrinkage may be due to the higher void content introduced by the incorporation of the rubber aggregates, which results in a porous mortar, as outlined [51-54]. The increase in drying shrinkage is caused by the evaporation of free water from macro pores. The rubber, in particular, may alter moisture diffusion through the matrix as well as the restraining effect of the rubber particles. Because the rubber aggregate exhibits a lower stiffness than the paste (and the sand aggregate), it may increase drying shrinkage. Figure $5 \mathrm{~b}$ shows the effect of silica fume and blast furnace slag on the evolution of the drying shrinkage with $5 \%$ RW. It can be seen that with the addition of SF and BFS, the drying shrinkage decreases with increasing time. The opposite effect was observed beyond 34 days; the decrement of drying shrinkage is more significant in mixtures with addition of SF.

On the other hand, in Figure $5 c$, with silica fume addition, there is a decrease in the drying shrinkage compared to the 10RW mix, but an increase is observed compared to the reference mixture. The opposite effect is seen with the addition of blast BFS, as a reduction in drying shrinkage compared to both the 10RW mix and the reference mix was promoted by the addition of BFS. It can be noted that, unlike SF, BFS presents a positive effect on drying shrinkage. The effect of the RW, SF, and BFS combination on the evolution of the drying shrinkage is shown in Figure 5d. It can be seen that with the addition of SF and BFS with $15 \% \mathrm{RW}$, the drying shrinkage decreases with time compared to the 15RW mixture and the reference mixture. However, the opposite effect is observed after 28 days: with the combination of SF and BFS with RW, the drying shrinkage increases compared to the reference mortar. The shrinkage is sensitive to the evaporation of the free water from the 
mixtures and the change of the shrinkage behavior may be related to the change of the pore structure and size distribution of the matrix, which affected the evaporation rate of the mixes.

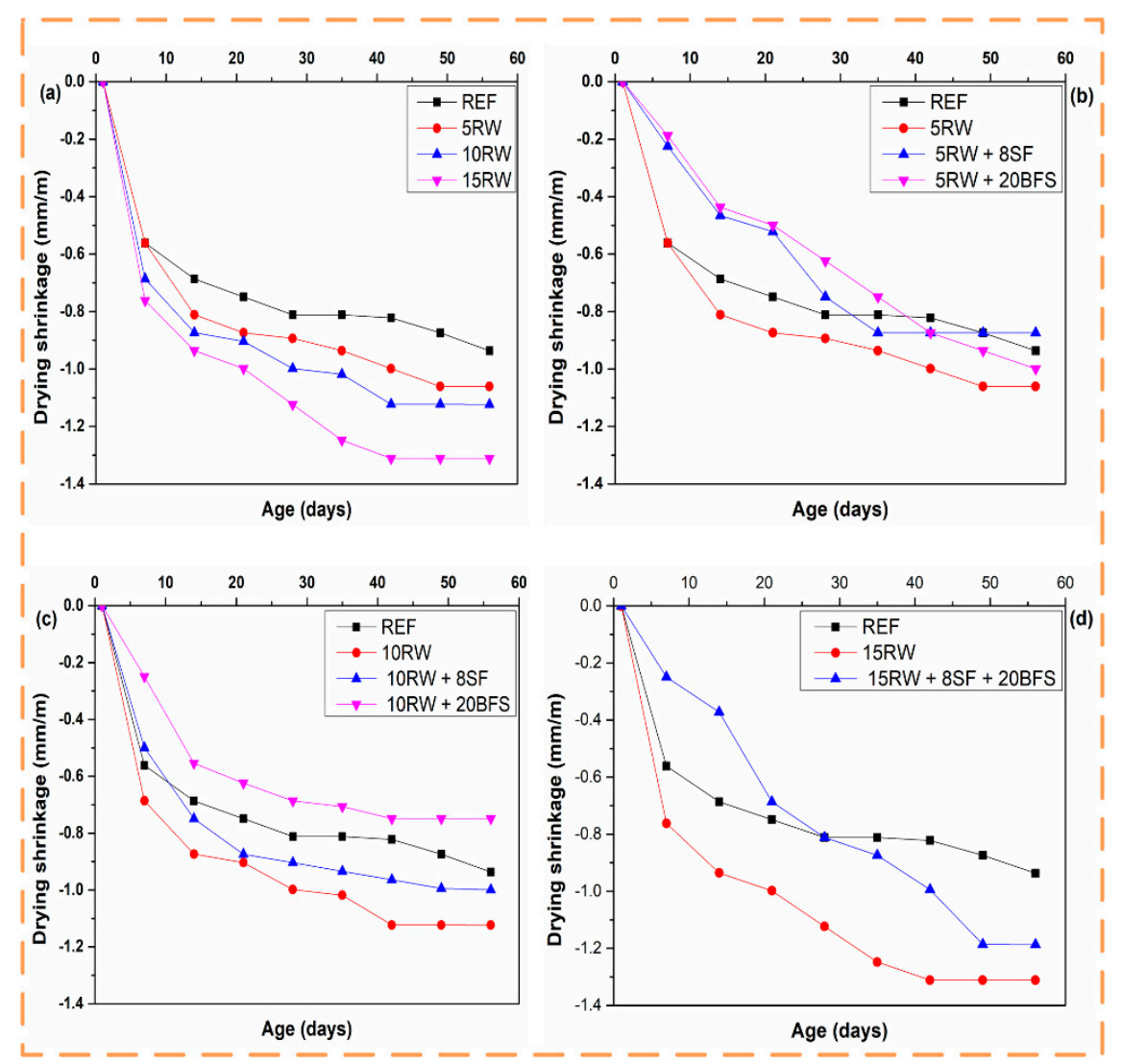

Figure 5. Drying shrinkage of the tested specimens: (a) mortars containing 5\%, 10\% and 15\%RW, (b) $5 \%$ RW with SF and BSF, (c) $10 \%$ RW with SF and BFS, (d) $15 \% \mathrm{RW}+8 \% \mathrm{SF}+20 \% \mathrm{BFS}$.

\subsection{Porosity Accessible to Water}

Figure 6 shows the results of the porosity accessible to water of all mixtures. A general increase in porosity is shown by the increase in rubber aggregates content in natural sand volume replacement compared to the reference mortar. Similar results are reported in other studies carried out on RW-based mortars [37] and rubberized concrete $[46,55,56]$. The order increases are $24.55,28.22$, and $30.42 \%$ for $5 \mathrm{RW}, 10 \mathrm{RW}$, and $15 \mathrm{RW}$, respectively, compared to the reference mortar. This increase can be linked to the non-polar character of the rubber aggregates according to $[57,58]$ and the trapped air trapped during the rubber compound mixing process according to [59]. At the interface between the rubber aggregates and the cement paste, this phenomenon generates porosity.

For mortars based on the combination of SF and BFS with RW, the results of wateraccessible porosities indicated reductions of 11.78 and $14.89 \%$, compared to the 5RW mixture, and of 6.19 and $11.39 \%$, compared to the $10 \mathrm{RW}$ mixture, with the addition of $8 \%$ SF and $20 \%$ BFS, respectively. This effect is mainly due to the increased quantity of hydration products produced by the pozzolanic reaction of SF and BFS with Portlandite, which is deposited within the cement matrix in the open pores and leads to a decrease in total porosity. The effect of the $\mathrm{RW}+\mathrm{SF}+\mathrm{BFS}$ combination on the water-accessible porosity shows a reduction of about $9.5 \%$ compared to the 15RW mixture. It is suggested that this decrease can be attributed to the filler effect of the BFS and SF during the mixing of the blends, as well as the formation and subsequent accumulation of hydration products within the available pore spaces of the hardened OPC $+\mathrm{SF}+\mathrm{BFS}$ mortars, resulting in the pore refinement and a consequent decrease of total porosity. 


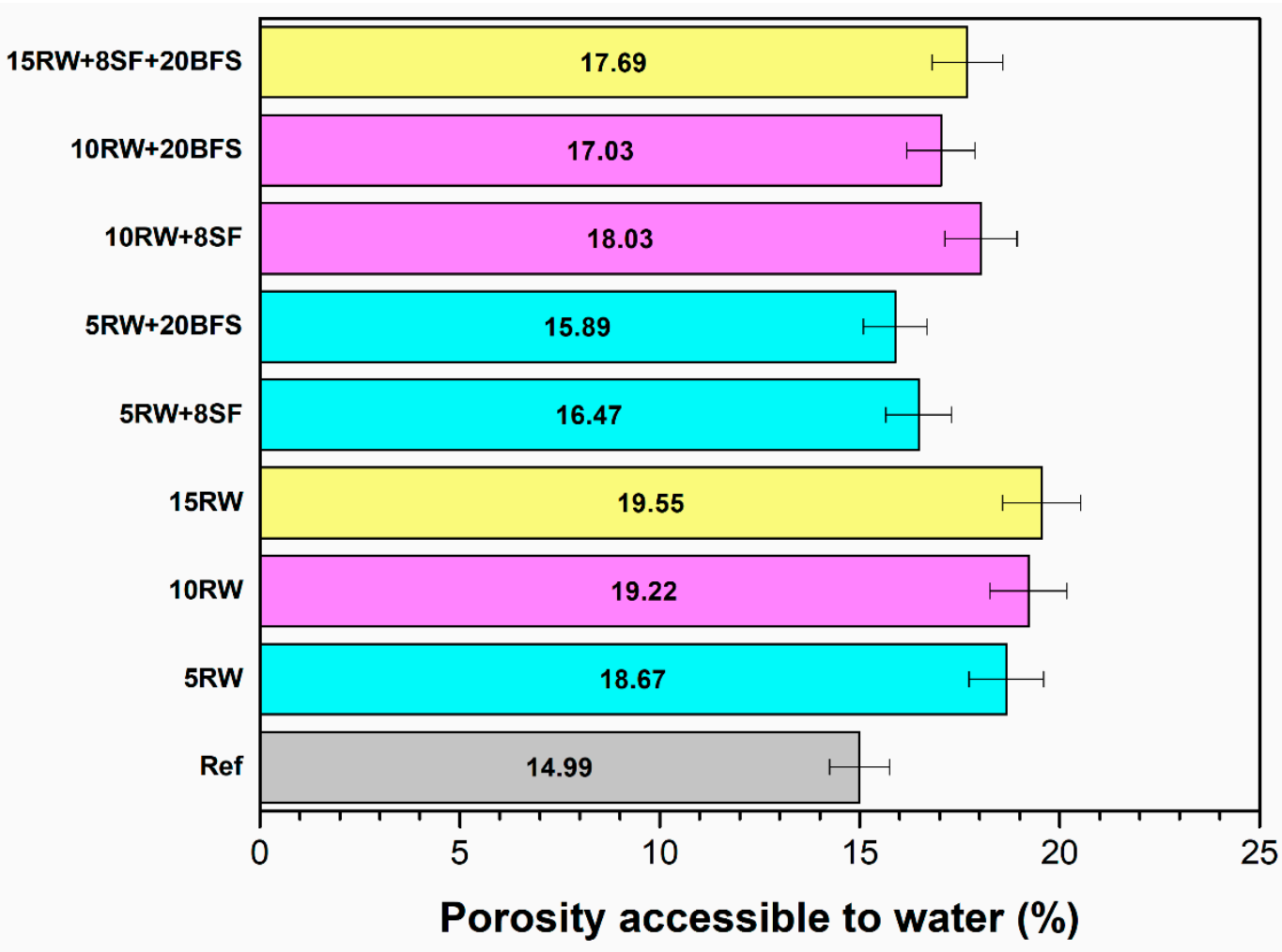

Figure 6. Porosity accessible to water of all mortars.

\subsection{Rapid Chloride Migration}

The relationship between the coefficient of chloride diffusion and the mortar composition is shown in Figure 7. It can be seen that the coefficient of diffusion of chloride decreases with the addition of RW $(5 \%, 10 \%$, and $15 \%)$ compared to the reference mortar. On the other hand, compared to mortars containing only RW, the diffusion coefficient decreases with the addition of SF and BSF. However, the chloride diffusion coefficient decreases for RW-based mortars with the addition of 5 to $10 \%$ RW replacement, further higher replacements up to $15 \%$ results in an increased diffusion coefficient. Other researchers have made similar conclusions. Onuaguluchi and Panesar [46] reported the rapid chloride permeability of concrete is reduced by partially replacing crumb rubber (size $86 \%$ smaller $2.3 \mathrm{~mm}$ ) with $5 \%$, $10 \%$, and $15 \%$ natural fine aggregate by volume. The inclusion of $5 \%$ rubber sand led to a decrease in chloride diffusion, whereas the coefficient of chloride diffusion increased when the replacement ratio increased from 5\% to 15\% [60]. Gupta et al. [61] found that the coefficients of chloride diffusion of rubber powder concrete (rubber powder replaced sand by $20 \%$ ) and hybrid rubber concrete (rubber powder replaced sand by $10 \%$ and rubber fibres replaced remaining sand by $25 \%$ ) decreased by $24.5 \%$ and $21.81 \%$, respectively, relative to NAC, and rubber powder filling effect could restrict the chloride effect. According to Zhu et al. [62], the chloride ion erosion resistance of CRC is significantly higher than that of NAC, especially when the temperature is below $20 \mathrm{C}$. From this research, it can be seen that, as mentioned by other researchers, rubberized mortars develop a better chloride ion penetration resistance due to the filling effect and the impermeable nature of the rubber particles. Owning to the higher activity and specific surface area of SF, the chloride binding capacity of the rubberized mortar with SF is stronger than that with BFS. Therefore, these mortars can be recommended as effective materials for the prevention of reinforcement corrosion in various structures. 


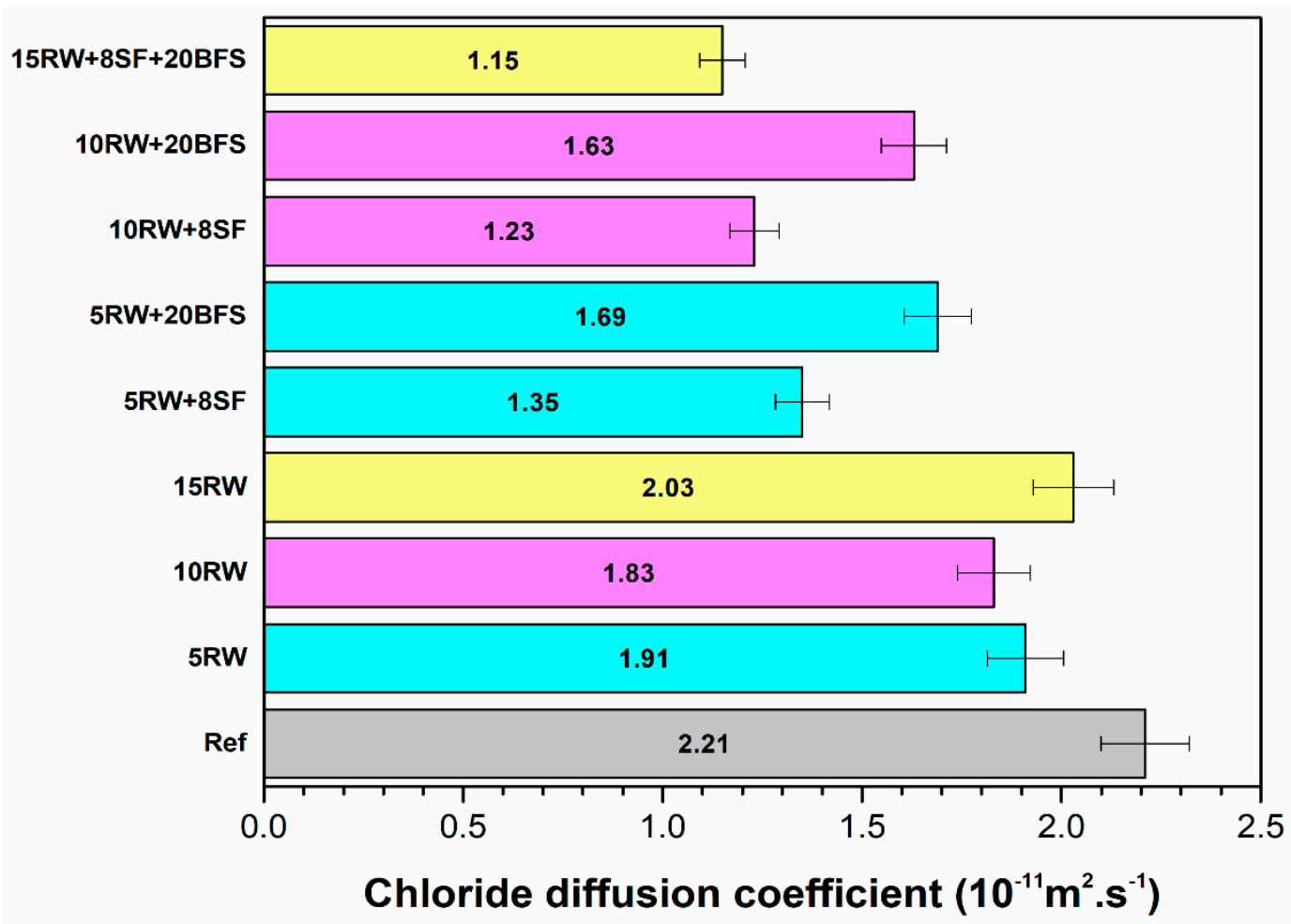

Figure 7. Chloride diffusion coefficient of all mortars.

\subsection{XRD Analysis}

The XRD patterns of OPC, OPC $+8 \%$ SF, OPC $+20 \%$ BFS and OPC $+8 \% S F+20 \%$ BFS pastes composites at 28-day curing age are shown in Figure 8. In OPC pastes, Portlandite, Calcite, Lime, Calcium silicate-hydrate (C-S-H), and Quartz have been observed. These phases are commonly observed in hydrated cement for 28 days [63]. While $\mathrm{Ca}_{54} \mathrm{MgAl}_{2} \mathrm{Si}_{16} \mathrm{O}_{90}$ and Ettringite were detected, lime and calcium silicate-hydrate (C-S-H) were suppressed with SF addition. K2Ag4S3 was detected when BFS was added, while Lime was suppressed. The addition of SF and BFS combinations led to the suppression of Lime and the appearance of $\mathrm{Ca}_{54} \mathrm{MgAl}_{2} \mathrm{Si}_{16} \mathrm{O}_{90}$. At the same time, with the addition of this combination, it can be observed that the quantity of portlandite has significantly decreased (almost disappeared).

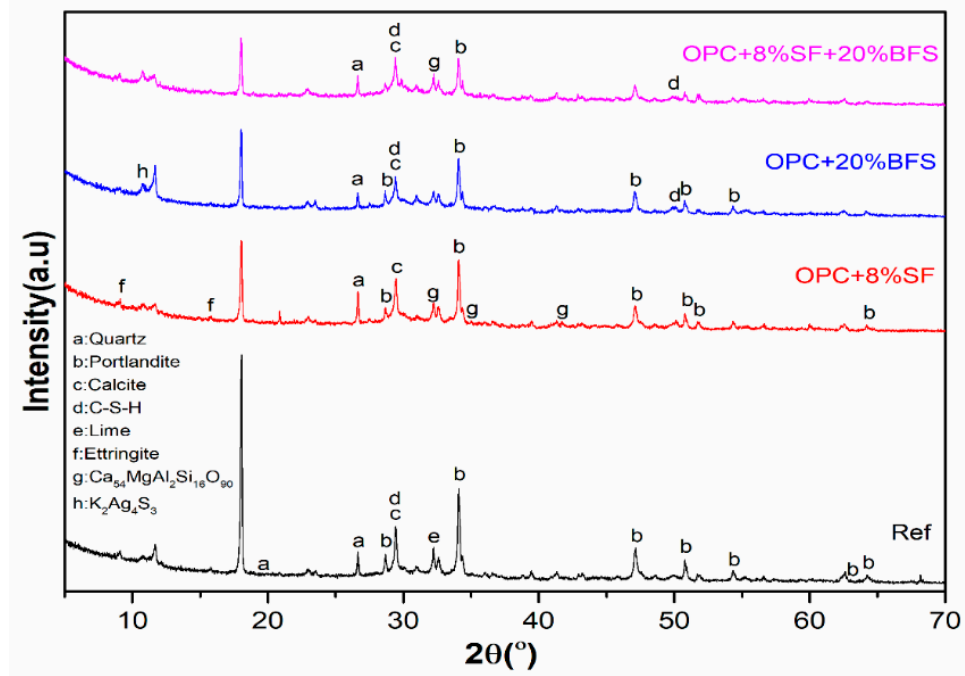

Figure 8. XRD patterns of: $\mathrm{OPC}, \mathrm{OPC}+\mathrm{SF}, \mathrm{OPC}+\mathrm{BFS}$ and $\mathrm{OPC}+\mathrm{SF}+\mathrm{BFS}$ pastes composites at 28 days. 


\subsection{SEM Analysis}

In order to analyze the influence of RW, SF, and BFS particles on the microstructure of rubberized mortars, BSE tests were performed on five selected mixtures at 420 days. The photos of BSE obtained are presented in Figure 9. Figure 9a-e show the reference mortar, the $10 \% \mathrm{RW}$ mortar, $10 \% \mathrm{RW}+8 \% \mathrm{SF}, 10 \% \mathrm{RW}+20 \% \mathrm{BFS}$, and $15 \% \mathrm{RW}+8 \% \mathrm{SF}+20 \% \mathrm{BFS}$, respectively, and images with $100 \times$ magnification were taken at several different locations. In the cement matrix, the natural sand is embedded and, as shown in Figure 9a, the interface between the sand and the matrix is compact for reference mortar. Unhydrated/partially hydrated cement particles represent the white (portlandite) and intermediate grey (clinker) elements.
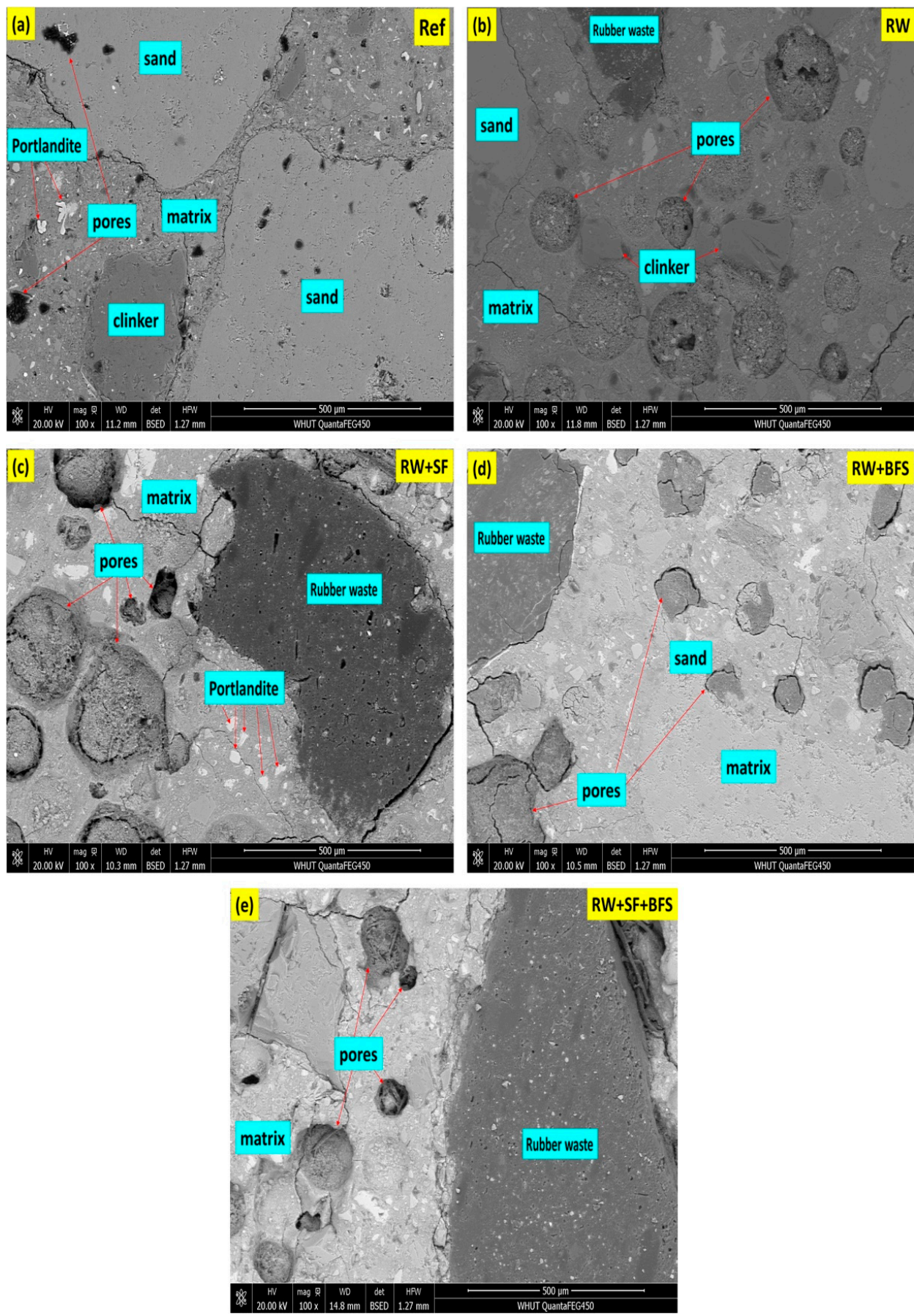

Figure 9. BSE micrograph of mortar samples at magnification of 100: (a) Ref, (b) RW, (c) RW+SF, (d) RW+BFS and (e) RW+SF+BFS. 
The darker features are rubber waste. Poor adhesion between the rubber particles and the cement paste was evident (see Figure 9b) (in Mixes with RW). According to [64], this effect could be due either to (a) the absence of bonding and the limited hydration of cement in the ITZ rubber cement paste, (b) the detachment of rubber during the preparation of the specimen, or (c) the combination of the two and (d) the non-polar nature of the rubber surface itself [65]. Interfacial bonding could perhaps be attributed to the compressive and flexural strength reduction [65]. Indeed, the incorporation of rubber aggregates results in a porous mortar likely to be related to the non-polar nature of rubber aggregates in accordance with $[57,58]$ and to the trapped air trapped during the mixing of rubber compounds in accordance with [59]. As illustrated in Figure 9b, this phenomenon generates porosity at the interface between rubber aggregates and cement paste.

Figure 9c,d show SEM observations of 10RW+8SF and 10RW+20BFS samples. The improved integration of the rubber particles in the RW+SF mix (Figure 9c) highlights the filling effect of SF and SEM observations indicate that the use of SF has improved the bonding of the mixtures between the rubber and the cement paste [64]. Rubber particles were better adhered to cement paste, similar to the behavior observed by Pelisser et al. [66] and Gupta et al. [67]. In the cement matrix of the RW+SF and RW+BFS samples, Figure 9c,d show many pores. On the other hand, the images show that the pores are not empty, unlike the samples containing only RW. Such pores are likely to contain SF and BFS, which could explain the improvement of these samples' mechanical and durability features.

Figure 9e shows the same observations as Figure 9c,d, except that for $15 R W+S F+B F S$ samples, the number of pores is more significant but empty. The images also reveal cracks between the cement paste and the fine aggregate/RW across the Interfacial Transition Zone (ITZ) (Figure 9a-e). This cracking can be attributed to the cement paste's shrinkage. Additional support to explain the change in mechanical properties and durability of the rubberized mortar is provided by the above observations.

\section{Conclusions}

In this study, several important performances of rubberized cement material with additives such as silica fume and blast furnace slag are evaluated and discussed. The results of compressive strength demonstrate that the incorporation of SF and BFS leads to an increase in strength. Substituting $8 \%$ of cement with SF increased the compressive strength of the 10RW mix by $28.36 \%$ for 7 days and substituting $20 \%$ of cement with BFS increased the compressive strength of the of the same mix by $30 \%$ and $28.93 \%$ for 7 and 28 days, respectively. Compared to the 15\% RW mix, the combination of $8 \%$ SF and $20 \%$ BFS with $15 \%$ RW increases the compressive strength by $26.30 \%$ and $24.63 \%$ for 7 and 28 days, respectively. As shown in SEM images, the use of silica fumes in mortar helps to fill the voids caused by the increase in rubber particles, mainly in ITZ. The introduction of SF and BFS has had a positive effect on the shrinkage of rubberized mortars. Compared to the reference mortar, there is an increase in the porosity of blends made with rubber aggregates. This increase is likely to be linked to the non-polar nature of the rubber aggregates and the trapped air trapped by the rubber compounds during mixing. With the combination of SF and BFS with RW, the results indicate reductions in porosity. The results indicated reductions of 11.78 and $14.89 \%$, compared to the $5 \mathrm{RW}$ mixture. This reduction is due to the formation and subsequent accumulation within the available pore spaces of the hardened mortars of hydration products, resulting in the refinement of the total pore system, resulting in a reduction of total porosity. The rapid chloride migration test showed that the resistance of mixtures to chloride penetration was improved by RW. The addition of SF and BFS to mixtures greatly improved resistance to the permeability of chloride. The hybrid rubber mortar is highly resistant to chloride penetration (mixing rubber powder, SF, and BFS). 
Author Contributions: Conceptualization, S.L., M.J., and X.G.; formal analysis, M.T.; funding acquisition, S.L.; investigation, M.T., S.B., and C.L.; methodology, M.T., S.L., M.J., X.G., M.L.B., S.B., and C.L.; visualization, S.L., M.J., and X.G.; Writing-original draft, M.T.; writing-review and editing, M.T., S.L., X.G., and M.L.B. All authors have read and agreed to the published version of the manuscript.

Funding: This research was funded by China Scholarship Council, grant number 2017DFJ008122.

Data Availability Statement: All data generated or analyzed during this study are included in this article.

Acknowledgments: The authors acknowledge the support by China Scholarship Council.

Conflicts of Interest: The authors declare no conflict of interest.

\section{References}

1. Yung, W.H.; Yung, L.C.; Hua, L.H. A study of the durability properties of waste tire rubber applied to self-compacting concrete. Constr. Build. Mater. 2013, 41, 665-672. [CrossRef]

2. Suhendro, B. Toward green concrete for better sustainable environment. Procedia Eng. 2014, 95, 305-320. [CrossRef]

3. Mehta, P.K. Reducing the Environmental Impact of Concrete. Concr. Int. 2001, 23, 61-66.

4. Boukour, S.; Benmalek, M.L. Performance evaluation of a resinous cement mortar modified with crushed clay brick and tired rubber aggregate. Constr. Build. Mater. 2016, 120, 473-481. [CrossRef]

5. Karakurt, C. Microstructure properties of waste tire rubber composites: An overview. J. Mater. Cycles Waste Manag. 2015, 17, 422-433. [CrossRef]

6. Gigli, S.; Landi, D.; Germani, M. Cost-benefit analysis of a circular economy project: A study on a recycling system for end-of-life tyres. J. Clean. Prod. 2019, 229, 680-694. [CrossRef]

7. Yadav, J.S.; Tiwari, S.K. The impact of end-of-life tires on the mechanical properties of fine-grained soil: A Review. Environ. Dev. Sustain. 2019, 21, 485-568. [CrossRef]

8. Wang, Q.Z.; Wang, N.N.; Tseng, M.L.; Huang, Y.M.; Li, N.L. Waste tire recycling assessment: Road application potential and carbon emissions reduction analysis of crumb rubber modified asphalt in China. J. Clean. Prod. 2020, 249, 119411. [CrossRef]

9. Edeskär, T. Use of Tyre Shreds in Civil Engineering Applications: Technical and Environmental Properties. Ph.D. Thesis, Lulea University of Technology, Luleå, Sweden, 2006.

10. Siddique, R. Waste Materials and By-Products in Concrete; Springer Science \& Business Media: Berlin, Germany, 2007.

11. Connor, K.; Cortesa, S.; Issagaliyeva, S.; Meunier, A.; Bijaisoradat, O.; Kongkatigumjorn, N.; Wattanavit, K. Developing a Sustainable Waste Tire Management Strategy for Thailand; Worcester Polytechnic Institute: Worcester, MA, USA, 2013.

12. Liu, H.S.; Mead, J.L.; Stacer, R.G. Environmental Impacts of Recycling Rubber in Light Fill Applications: Summary and Evaluation of Existing Literature; University of Massachusetts, Chelsea Center for Recycling and Economic Development: Amherst, MA, USA, 1998.

13. Thomas, B.S.; Gupta, R.C. Properties of high strength concrete containing scrap tire rubber. J. Clean. Prod. 2016, 113, 86-92. [CrossRef]

14. Ganjian, E.; Khorami, M.; Maghsoudi, A.A. Scrap-tyre-rubber replacement for aggregate and filler in concrete. Constr. Build. Mater. 2009, 23, 1828-1836. [CrossRef]

15. Valente, M.; Sibai, A. Rubber/crete: Mechanical properties of scrap to reuse tire-derived rubber in concrete; A review. J. Appl. Biomater. Funct. Mater. 2019, 17. [CrossRef]

16. Sambucci, M.; Marini, D.; Sibai, A.; Valente, M. Preliminary Mechanical Analysis of Rubber-Cement Composites Suitable for Additive Process Construction. J. Compos. Sci. 2020, 4, 120. [CrossRef]

17. Segre, N.; Joekes, I. Use of tire rubber particles as addition to cement paste. Cem. Concr. Res. 2000, 30, 1421-1425. [CrossRef]

18. El-Gammal, A.; Abdel-Gawad, A.K.; El-Sherbini, Y.; Shalaby, A. Compressive strength of concrete utilizing waste tire rubber. J. Emerg. Trends Eng. Appl. Sci. 2010, 1, 96-99.

19. Aniruddh, A.; Kumar, A.; Khan, M.A. Effect on compressive strength of concrete by using waste rubber as partial replacement of fine aggregate: A review. Int. Res. J. Eng. Technol. 2016, 3, 86-89.

20. Granju, J.L.; Chausson, H. Serviceability of fiber reinforced thin overlays relation between cracking and debonding. In Proceedings of the ConChem International Exhibition \& Conference, Brussels, Belgium, 28-30 November 1995; Verlag für chemische industrie: Thannhausen, Germany; pp. 133-142.

21. Aslani, F.; Ma, G.; Law, D.; Wan, Y.; Xuan, V.; Le, T. Experimental investigation into rubber granules and their effects on the fresh and hardened properties of self-compacting concrete. J. Clean. Prod. 2018, 172, 1835-1847. [CrossRef]

22. Khalil, E.; Abd-Elmohsen, M.; Anwar, A.M. Impact Resistance of Rubberized Self-Compacting Concrete. Water Sci. 2015, 29, 45-53. [CrossRef]

23. Atahan, A.O.; Yücel, A.Ö. Crumb rubber in concrete: Static and dynamic evaluation. Constr. Build. Mater. 2012, 36, 617-622. [CrossRef]

24. Aslani, F. Mechanical properties of waste tire rubber concrete. J. Mater. Civ. Eng. 2015, 28, 04015152. [CrossRef] 
25. Topçu, I.B.; Bilir, T. Experimental investigation of some fresh and hardened properties of rubberized self-compacting concrete. Mater. Des. 2009, 30, 3056-3065. [CrossRef]

26. Grdić, Z.; Topličić-Curčić, G.; Ristić, N.; Grdić, D.; Mitković, P. Hydro-abrasive resistance and mechanical properties of rubberized concrete. Građevinar 2014, 66, 11-20.

27. Huang, X.; Ranade, R.; Ni, W.; Li, V.C. On the use of recycled tire rubber to develop low E-modulus ECC for durable concrete repairs. Constr. Build. Mater. 2013, 46, 134-141. [CrossRef]

28. Raghavan, D.; Huynh, H.; Ferraris, C.F. Workability, mechanical properties and chemical stability of a recycled tyre rubber filled cementitious composite. J. Mater. Sci. 1998, 33, 1745-1752. [CrossRef]

29. Cairns, R.A.; Kew, H.Y.; Kenny, M.J. The Use of Recycled Rubber Tyres in Concrete Construction; The University of Strathclyde: Glasgow, Scotland, 2004.

30. Oikonomou, N.; Stefanidou, M.; Mavridou, S. Improvement of the bonding between rubber tire particles and cement paste in cement products. In Proceedings of the 15th Conference of the Technical Chamber of Greece, Alexandroupoli, Greece, 25-27 October 2006; pp. 234-242.

31. Chou, L.H.; Lin, C.N.; Lu, C.K.; Lee, C.H.; Lee, M.T. Improving rubber concrete by waste organic sulfur compounds. Waste Manag. Res. 2010, 28, 29-35. [CrossRef]

32. Dong, Q.; Huang, B.; Shu, X. Rubber modified concrete improved by chemically active coating and silane coupling agent. Constr. Build. Mater. 2013, 48, 116-123. [CrossRef]

33. Xie, J.; Fang, C.; Lu, Z.; Li, Z.; Li, L. Effects of the addition of silica fume and rubber particles on the compressive behaviour of recycled aggregate concrete with steel fibres. J. Clean. Prod. 2018, 197, 656-667. [CrossRef]

34. Copetti, C.M.; Borges, P.M.; Squiavon, J.Z.; da Silva, S.R.; de Oliveira Andrade, J.J. Evaluation of tire rubber surface pre-treatment and silica fume on physical-mechanical behavior and microstructural properties of concrete. J. Clean. Prod. 2020, 256, 120670. [CrossRef]

35. Al-Akhras, N.M.; Smadi, M.M. Properties of tire rubber ash mortar. Cem. Concr. Comp. 2004, 26, 821-826. [CrossRef]

36. Yilmaz, A.; Degirmenci, N. Possibility of using waste tire rubber and fly ash with Portland cement as construction materials. Waste Manag. 2009, 29, 1541-1546. [CrossRef]

37. Turki, M.; Zarrad, I.; Bretagne, E.; Quéneudec, M. Influence of filler addition on mechanical behavior of cementitious mortarrubber aggregates: Experimental study and modeling. J. Mater. Civ. Eng. 2012, 24, 1350-1358. [CrossRef]

38. Aslani, F.; Gedeon, R. Experimental investigation into the properties of self-compacting rubberised concrete incorporating polypropylene and steel fibers. Struct. Concr. 2018, 20, 267-281. [CrossRef]

39. Sadiq, M.R.; Javed, M.F.; Ullah, S.; Din, N. Effect of PVA on Rubberized Concrete. In Proceedings of the 1st Conference on Sustainability in Civil Engineering, Capital University of Science and Technology, Islamabad, Pakistan, 1 August 2019; pp. 1-7.

40. Han, Q.; Yang, Y.; Zhang, J.; Yu, J.; Hou, D.; Dong, B. Insights into the interfacial strengthening mechanism of waste rubber/cement paste using polyvinyl alcohol: Experimental and molecular dynamics study. Cem. Concr. Compos. 2020, 114, 103791. [CrossRef]

41. Yu, J.; Wang, N.; Wang, M.; Zhang, J.; Hou, D. Recyclable rubber-cement composites produced by interfacial strengthened strategy from polyvinyl alcohol. Constr. Build. Mater. 2020, 264, 120541. [CrossRef]

42. Wang, J.; Dai, Q.; Si, R.; Guo, S. Investigation of properties and performances of Polyvinyl Alcohol (PVA) fiber-reinforced rubber concrete. Constr. Build. Mater. 2018, 193, 631-642. [CrossRef]

43. Güneyisi, E.; Gesoğlu, M.; Özturan, T. Properties of rubberized concretes containing silica fume. Cem. Concr. Res. 2004, 34, 2309-2317. [CrossRef]

44. Noaman, A.T.; Bakar, B.H.A.; Akil, H.M. Experimental investigation on compression toughness of rubberized steel fibre concrete. Constr. Build. Mater. 2016, 115, 163-170. [CrossRef]

45. González-Fonteboa, B.; Martínez-Abella, F. Concretes with aggregates from demolition waste and silica fume. Mater. Mech. Prop. Build. Environ. 2008, 43, 429-437.

46. Onuaguluchi, O.; Panesar, D.K. Hardened properties of concrete mixtures containing pre-coated crumb rubber and silica fume. J. Clean. Prod. 2014, 82, 125-131. [CrossRef]

47. Na, O.; Xi, Y. Mechanical and durability properties of insulation mortar with rubber powder from waste tires. J. Mater. Cycles Waste Manag. 2017, 19, 763-773. [CrossRef]

48. Gesoglu, M.; Güneyisi, E.; Hansu, O.; Ipek, S.; Asaad, D.S. Influence of waste rubber utilization on the fracture and steel-Concrete bond strength properties of concrete. Constr. Build. Mater. 2015, 101, 1113-1121. [CrossRef]

49. Bompa, D.V.; Elghazouli, A.Y. Bond-slip response of deformed bars in rubberised concrete. Constr. Build. Mater. 2017, 154, 884-898. [CrossRef]

50. Ramezanianpour, A.A.; Moeini, M.A. Mechanical and durability properties of alkali activated slag coating mortars containing nanosilica and silica fume. Constr. Build. Mater. 2018, 163, 611-621. [CrossRef]

51. Pedro, D.; de Brito, J.; Veiga, R. Mortars made with fine granulate from shredded tires. J. Mater. Civ. Eng. 2012, 25, 519-529. [CrossRef]

52. Benazzouk, A.; Douzane, O.; Langlet, T.; Mezreb, K.; Roucoult, J.M.; Quéneudec, M. Physico-mechanical properties and water absorption of cement composite containing shredded rubber wastes. Cem. Concr. Compos. 2007, 29, 732-740. [CrossRef]

53. Sukontasukkul, P.; Tiamlom, K. Expansion under water and drying shrinkage of rubberized concrete mixed with crumb rubber with different size. Constr. Build. Mater. 2012, 29, 520-526. [CrossRef] 
54. Benazzouk, A.; Douzane, O.; Mezreb, K.; Que, M. Physico-mechanical properties of aerated cement composites containing shredded rubber waste. Cem. Concr. Compos. 2006, 28, 650-657. [CrossRef]

55. Turgut, P.; Yesilata, B. Physico-mechanical and thermal performances of newly developed rubber-added bricks. Energy Build. 2008, 40, 679-688. [CrossRef]

56. Karahan, O.; Özbay, E.; Hossain, K.M.; Lachemi, M.; Atis, C.D. Fresh, mechanical, transport, and durability properties of self-consolidating rubberized concrete. ACI Mater. J. 2012, 109, 413-420.

57. Siddique, R.; Naik, T.R. Properties of concrete containing scrap-tire rubber-An overview. Waste Manag. 2004, $24,563-569$. [CrossRef] [PubMed]

58. Sukontasukkul, P. Use of crumb rubber to improve thermal and sound properties of pre-cast concrete panel. Constr. Build. Mater. 2009, 23, 1084-1092. [CrossRef]

59. Benazzouk, A.; Douzane, O.; Langlet, T.; Mezreb, K.; Labbani, F.; Roucoult, J.M. Effet des granulats de caoutchouc sur les propriétés d'un mortier de ciment. In Réunion Internationale des Laboratoires et Experts des Matériaux; Université Claude Bernard Lyon 1: Villeurbanne, France, 2008.

60. Bravo, M.; De Brito, J. Concrete made with used tyre aggregate: Durability-related performance. J. Clean. Prod. 2012, 25, 42-50. [CrossRef]

61. Gupta, T.; Siddique, S.; Sharma, R.K.; Chaudhary, S. Behaviour of waste rubber powder and hybrid rubber concrete in aggressive environment. Constr. Build. Mater. 2019, 217, 283-291. [CrossRef]

62. Zhu, H.; Liang, J.; Xu, J.; Bo, M.; Li, J.; Tang, B. Research on anti-chloride ion penetration property of crumb rubber concrete at different ambient temperatures. Constr. Build. Mater. 2018, 189, 42-53. [CrossRef]

63. Jamsheer, A.F.; Kupwade-Patil, K.; Büyüköztürk, O.; Bumajdad, A. Analysis of engineered cement paste using silica nanoparticles and metakaolin using 29Si NMR, water adsorption and synchrotron X-ray Diffraction. Constr. Build. Mater. 2018, 180, 698-709. [CrossRef]

64. Raffoul, S.; Garcia, R.; Pilakoutas, K.; Guadagnini, M.; Medina, N.F. Optimisation of rubberised concrete with high rubber content: An experimental investigation. Constr. Build. Mater. 2016, 124, 391-404. [CrossRef]

65. Najim, K.B.; Hall, M.R. Crumb rubber aggregate coatings/pre-treatments and their effects on interfacial bonding, air entrapment and fracture toughness in self-compacting rubberised concrete (SCRC). Mater. Struct. 2013, 46, 2029-2043. [CrossRef]

66. Pelisser, F.; Zavarise, N.; Longo, T.A.; Bernardin, A.M. Concrete made with recycled tire rubber: Effect of alkaline activation and silica fume addition. J. Clean. Prod. 2011, 19,757-763. [CrossRef]

67. Gupta, T.; Chaudhary, S.; Sharma, R.K. Assessment of mechanical and durability properties of concrete containing waste rubber tire as fine aggregate. Constr. Build. Mater. 2014, 73, 562-574. [CrossRef] 